\title{
A EPISTEMOLOGIA DA PRÁXIS COMO FENÔMENO FORMADOR DO/A DOCENTE: UM CAMINHO POSSÍVEL?
}

\author{
LA EPISTEMOLOGIA DE LA PRAXIS COMO FENÓMENO FORMADOR \\ DEL / LA DOCENTE: UN CAMINO POSIBLE?
}

\section{THE EPISTEMOLOGY OF PRAXIS AS A FORMATIVE PHENOMENON OF THE TEACHER: A POSSIBLE WAY?}

\author{
Jerry Adriano RAIMUNDO ${ }^{1}$ \\ Maurício FAGUNDES ${ }^{2}$
}

\begin{abstract}
RESUMO: Este artigo tem por objetivo problematizar as possibilidades e os limites da formação continuada desenvolvida por meio do exercício da epistemologia da práxis do/a professor/a, como resultante de seu trabalho docente. A epistelomologia da práxis desenvolvida neste artigo fundamenta-se no materialismo histórico dialético, como base para a construção de conhecimentos de uma formação crítica e emancipadora. Os sujeitos desta investigação foram professores/as de anos iniciais de uma escola da rede pública do município de Curitiba, considerando as possibilidades e os limites desse processo. A pesquisa foi um estudo de caso com abordagem qualitativa de natureza descritiva e no método dialético-materialista. Os principais referenciais teóricos utilizados foram: Bakhtin, Maria Isabel da Cunha, Paulo Freire, António Nóvoa, Augusto Nibaldo Silva Triviños, Adolfo Sanchez Vázquez e Álvaro Vieira Pinto. Os resultados apontam que é possível a formação por meio da práxis. Como limite, tem-se a formação de tendência pragmática e ativista.
\end{abstract}

PALAVRAS-CHAVE: Formação docente. Epistemologia da práxis. Existência.

RESUMEN: Este artículo tiene por objetivo problematizar las posibilidades y los límites de la formación continuada desarrollada por medio del ejercicio de la epistemología de la praxis del/la profesor/a, como resultante de su trabajo docente. La epistelomología de la praxis desarrollada en este artículo se fundamenta en el materialismo histórico dialéctico, como base para la construcción de conocimientos de una formación crítica y emancipadora. Los sujetos de esta investigación fueron profesores/as de años iniciales de una escuela de la red pública del municipio de Curitiba, considerando las posibilidades y los límites de ese proceso. La investigación fue un estudio de caso con abordaje cualitativo de naturaleza descriptiva y en el método dialéctico-materialista. Los principales referenciales teóricos utilizados fueron: Mikhail Bakhtin, Maria Isabel da Cunha, Paulo Freire, António Nóvoa, Augusto Nibaldo Silva Triviños, Adolfo Sanchez Vázquez e

\footnotetext{
1 Secretaria Municipal de Educação de Curitiba (SME), Curitiba - PR - Brasil. Mestre em Educação. ORCID: <http://orcid.org/0000-0002-1598-110X>. E-mail: prof_jerry@hotmail.com

${ }^{2}$ Universidade Federal do Paraná (UFPR) - Matinhos - PR - Brasil. Setor Litoral. Doutor em Educação. ORCID: <http://orcid.org/0000-0003-3623-2973>. E-mail: mauriciovitoriafagundes@gmail.com
} 
Álvaro Vieira Pinto. Los resultados apuntan que es posible la formación por medio de la praxis. Como límite, se tiene la formación de tendencia pragmática y activista.

PALAVRAS CLAVE: Formación docente. Epistemologia de la práxis. Existencia.

ABSTRACT: This article aims to problematize the possibilities and the limits of continuing education developed by the teacher's epistemology of praxis as a result of his/her teaching practice. The epistelomology of praxis developed in this article is based on dialectical historical materialism, as a basis for the construction of knowledge of a critical and emancipatory formation. The subjects of this study were teachers of a public elementary school of the city of Curitiba, whose possibilities and limits in this process were considered. This research was a case study on qualitative approach of descriptive nature and on the dialectical materialism method. The main authors used as theoretical references are: Mikhail Bakhtin, Maria Isabel da Cunha, Paulo Freire, António Nóvoa, Augusto Nibaldo Silva Triviños, Adolfo Sanchez Vázquez and Álvaro Vieira Pinto.. The results indicate that the formation through praxis is possible, as a limit to the pragmatic formation and activism.

KEYWORDS: Teacher training. Epistemology of praxis. Existence.

\section{Introdução}

As políticas educacionais brasileiras, assumidas a partir da década de 1990 vem se desenvolvendo no tensionamento entre os ventos democratizantes, do período pós-ditadura militar, e na influência internacional, baseada na política neoliberal.

Temos verificado, dia após dia, que as políticas neoliberais vêm se sobrepondo aos incipientes processos democráticos e construindo uma agenda no campo da educação, com ações, por exemplo, de implantação de currículos homogeneizadores, objetivando uma formação carregada da perspectiva técnica e esvaziada da perspectiva filosófica, sociológica e humana, projetando assim, a formação de pessoas sujeitadas ao mercado de trabalho e suas demandas lucrativas.

A formação de professores/as em serviço tem sido, de modo geral, tratada pela perspectiva de 'formação continuada', e concebida normalmente, como cursos, palestras e pluralidade de reuniões que, previstas por lei, cumpre a função de atualização e formação profissional - geralmente oferecida por núcleos e secretarias de educação, de forma pontual, desconexas e na forma de treinamento (CURITIBA, 2016a).

Porém, a dialética nos diz que o contrário também é possível. Em concordância com a perspectiva de Freire (1996), a formação independentemente de sua qualificação, 
vem imbricada na "experiência histórica, política, cultural e social dos homens e das mulheres jamais poder se dar 'virgem' do conflito entre as forças que obstaculizam a busca da assunção de si [...]” (p. 24), portanto, enuncia a progressão educacional em que a pessoa, que é também professor/a, combina conhecimentos de suas vivências com conhecimentos da prática educacional, a pessoa se forma na ação de correlacioná-los e de assumi-los em si.

Para compreender a materialidade dialética do processo de formação pelo fenômeno da epistemologia da práxis, este artigo assume como objetivo: compreender o processo formativo de docentes, de anos iniciais de uma escola da rede pública do município de Curitiba, nas possibilidades e nos limites de seu próprio trabalho concebido como práxis.

O caminho metodológico da pesquisa que constituiu este artigo fundamentou-se no materialismo histórico dialético com a intencionalidade de realizar uma imersão na realidade dos fenômenos estudados, guiados pela totalidade, possível, de seus sujeitos e de suas práticas docentes, como possibilidade de fugir de uma abordagem simplificadora ou reducionista da operação do fenômeno, como corroborou Vieira Pinto (1985).

Para apreensão da materialidade dos fenômenos a pesquisa assumiu a perspectiva do 'estudo de caso' (TRIVIÑOS, 1987), em virtude de reunir diversas informações para descrever um fenômeno específico, que no caso é a formação docente pelo fenômeno da epistemologia da práxis. Sendo assim, amplia a rigorosidade da pesquisa destacar que:

a epistemologia, entendida em sentido dialético, previne-nos igualmente de cair no engano de conceber a ciência como efeito da racionalidade abstrata, de que o ser humano estaria dotado, por representar a essência do seu espírito, a qual produziria o saber metódico por necessidade interior, operando pelo impulso irresistível de captar a maior soma de dados objetivos e submetê-los às suas leis a priori (VIEIRA PINTO, 1985, p. 71).

O caso estudado teve como lócus uma escola da rede pública municipal de Curitiba, escolhida por estar localizada num bairro muito antigo do município e que se configura, por ter uma realidade de grande exclusão de seus sujeitos, manifestada na situação de pobreza, miséria, riscos relacionados ao crime e tráfico, configurando uma situação de vulnerabilidade social (CURITIBA, 2017). Com estas características, a escola é composta por estudantes que demandam conhecimento cognitivo, social, cultural, 
humanização etc., ou seja: é uma escola que demanda práxis - fato que justifica a sua escolha. Portanto, um desafio para este estudo.

Como instrumento de coleta de dados foi utilizada a entrevista semiestruturada, observação e análise de documentos. Os sujeitos de pesquisa foram duas professoras atuantes em sala de aula e dois pedagogos. O critério de escolha dos sujeitos levou em consideração o maior tempo de trabalho na área, compromisso pessoal com os objetivos sociais da educação, expressão (teoria e prática) no trabalho e atributos de realizar trabalho de boa qualidade. Os sentidos, dos fenômenos, foram interpretados com base na análise dos discursos (BAKHTIN, 1997). As relações dos discursos são analisadas dialeticamente a fim de promover os resultados com a síntese provisória desta pesquisa.

Este artigo principia com uma breve exposição sobre a práxis como fenômeno formativo, seguido dos achados na análise documental; percepções dos entrevistados; da apresentação dos fatores que impulsionam e fatores que inibem a formação continuada do/a docente pelo fenômeno da práxis e, finalizando, com as considerações provisórias.

\section{A epistemologia da práxis como fenômeno formativo}

A concepção de epistemologia da práxis que permeia este estudo está além do reducionismo de 'teoria e prática'. De acordo com Veira Pinto (1985, p. 69), “a epistemologia representa a teoria da ciência”, que neste estudo, constitui-se por meio da visão de totalidade do real e na concepção filosófica de práxis, como forma de dar suporte às análises do objeto deste estudo, que é a formação continuada dos docentes. Nesse entendimento, por meio da epistemologia da práxis, assumimos que o ponto de partida para conhecer o processo de formação docente, suas ideias e representações assentam-se nos homens e mulheres "em sua atividade real, e é a partir de seu processo de vida real que representamos também o desenvolvimento dos reflexos e das repercussões ideológicas desse processo vital" (MARX; ENGELS, 2001, p. 19).

Vázquez (1977) traduz a palavra práxis, do grego, como ação de efeito moral. No entanto, a partir de Marx e Engels (2001) o conceito de práxis progride da dimensão moral para a condição de trabalho, propriamente na finalidade do trabalho.

Assim sendo, a epistemologia da práxis tem um sentido ontológico através da existência; porque, existindo o homem, por meio do trabalho, apreende a natureza e a transforma para a sua humanização. Com esse processo o homem objetiva o seu trabalho 
na transformação da natureza e subjetiva a sua feitura identificando as características humanas que imprimiu na natureza. No desenrolar histórico, esta ação de transformação da natureza modifica o próprio homem, que se transforma ontologicamente por meio do seu próprio trabalho.

Deste modo, segundo Marx e Engels (2001, p. 19), "a vida determina a consciência do homem", pelo seu progresso orgânico e sua posição diante da realidade o homem se encontra existente na integração com a natureza, "o homem só existe na relação prática com a natureza", assegura Vázquez (1977, p. 144).

Esta atividade de transformar a natureza é conhecida como trabalho, afirma Vázquez (1977). É com o trabalho que o homem se projeta na natureza, que aponta nela as suas intenções para que se ajuste às suas necessidades, convertendo a natureza pura em natureza humanizada. Esta transformação oferece sentido humano, em que na objetivação do homem, se reconhece nesta natureza transformada pela sua prática, como produto de seu trabalho.

A condição existencial que permite o homem/mulher se objetivar e subjetivar através do trabalho é a práxis, que confere a esse/a homem/mulher um sentido ontológico, o sentido que Freire (1979) concebe como 'ser mais', a possibilidade que o homem tem, pela práxis, de superar a si próprio.

A transformação da condição existencial não se efetua pela prática do trabalho individual, senão pela coletividade existencial que intenciona mesmo sentido de transformação. Por isso, a subjetivação não é apenas do próprio trabalho senão do efeito do trabalho coletivo, que repercute em outras práticas e outras subjetivações.

Nessa perspectiva que esta pesquisa investigou a epistemologia da práxis como fenômeno formativo, pois é na objetivação docente (trabalho) que o/a professor/a produz fenômenos de transformação, que ao serem observados podem ser subjetivados e assim modifica o/a próprio/a ator. Destarte, é na subjetivação do fenômeno de objetivação, ou no fenômeno da práxis que o/a docente se forma. Permeados por esta concepção, procuramos descobrir nos documentos e nos relatos dos entrevistados a possibilidade ou a impossibilidade da práxis ser fomentadora da formação continuada.

\section{O que anunciam os documentos sobre a formação docente e a práxis}


A análise do discurso documental partiu da seleção de documentos que organizam a educação e as ações docentes, a fim de identificar a formação permanente, em sua perspectiva de projeto, para fomentar a comparação com os discursos das entrevistas.

Selecionamos cinco documentos, dos quais pinçamos referências que abordam alguma menção de 'formação docente' e o conceito de práxis. Os documentos são: Diretrizes Curriculares Nacionais da Educação Básica (DCNEB); Diretrizes Curriculares para Educação Municipal de Curitiba (DCEMC); Currículo do Ensino Fundamental $1^{\circ}$ ao $9^{\circ}$ ano (CEF); Indicadores de Qualidade das Escolas Municipais de Curitiba (IQEMC); e, Projeto Político-Pedagógico (PPP).

\section{Diretrizes Curriculares Nacionais da Educação Básica - DCNEB}

O documento (BRASIL, 2013) confere como incumbência do PPP a inclusão de medidas de consolidação da identidade dos profissionais da educação, da identidade social do professor, da autonomia docente e indicadores de qualidade social da educação escolar - podendo ser incluídos, estas indicações, nos documentos municipais.

No enunciado "[...] hoje, exige-se do professor mais do que um conjunto de habilidades cognitivas, sobretudo se ainda for considerada a lógica própria do mundo digital e das mídias em geral, o que pressupõe aprender a lidar com os nativos digitais [...]" (BRASIL, 2013, p. 61), amplia a concepção de formação docente, pois não lhe é o bastante a especialização cognitiva de um tema, senão é preciso desenvolver habilidades além de sua própria formação. Traz, na continuidade do texto, a noção de formação cooperativa, que é uma habilidade contraditória às políticas neoliberais que acentuam o individualismo.

A formação que o documento sugere implica uma autogerência docente, pois segundo Brasil (2013), a/o docente deve agir além da técnica, seu exercício deve permear políticas, éticas e estéticas. A correlação de sentidos atribui à ação docente a dimensão social, política e ética. Assim, a ação docente é práxis na contemplação social que lhe faz agir segundo a sua autonomia consoante com a sua própria existência.

Deste modo, a ação docente não é individual, é coletiva e numa perspectiva de gestão democrática:

a prática em que os sujeitos constitutivos da comunidade educacional discutam a própria práxis pedagógica impregnando-a de entusiasmo e de compromisso com a sua própria comunidade, valorizando-a, situando-a no contexto das relações sociais e buscando soluções conjuntas (BRASIL, 2013, p. 78).

RIAEE - Revista Ibero-Americana de Estudos em Educação, Araraquara, v. esp, n. 3, p. 1935-1951, dez., 2018. E-ISSN: 1982-5587. 
O documento indica que a práxis não é apenas um conjunto de ações, mas é um desafio que a contemporaneidade propõe (BRASIL, 2013). Os desafios estão além da formação inicial e, por isso, implica em formação que se articule pela práxis, a fim de que a transformação-formativa do/a docente implique na transformação-formativa social. Esta teleologia implica o fenômeno da práxis que forma a/o docente.

\section{Diretrizes Curriculares para a Educação Municipal de Curitiba - DCEMC}

Este documento atualiza as antigas diretrizes/2006. Nele estão presentes poucas relações de práxis e formação, contudo, inicia a escrita com o sentido de autonomia profissional:

[...] o diálogo, a formação e a informação acerca dos espaços e instrumentos democráticos possibilitam o reforço da profissionalidade dos sujeitos e grupos sociais, resultando em maior AUTONOMIA na tomada de decisões. No entanto, na democracia, a autonomia será sempre relativa e social, devendo ser regulada pela legislação e pelos interesses públicos e coletivo e estar vinculada às condições para o acesso e fruição do direito à educação a todos e todas (CURITIBA, 2016, p. 7).

Esse documento enuncia a autonomia como um efeito da práxis, pois o sentido da ação democrática que aponta o esforço do trabalho para a sociedade resulta na autonomia e configura a auto formação docente nessa perspectiva de trabalho. A respeito da propalada autonomia, Nóvoa (2009, p. 20) alerta que:

quanto mais se fala da autonomia dos professores mais a sua ação surge controlada, por instâncias diversas, conduzindo a uma diminuição das suas margens de liberdade e de independência. $\mathrm{O}$ aumento exponencial de dispositivos burocráticos no exercício da profissão não deve ser visto como uma mera questão técnica ou administrativa, mas antes como a emergência de novas formas de governo e de controlo da profissão.

A partir desta crítica, é preciso aferir a autenticidade dos objetivos que o documento enuncia, pois na condição de relação lógica o texto enuncia a práxis, mas se o sentido se inclina para controle, pode implicar ações na dimensão da racionalidade técnica (CONTRERAS, 2012). 


\section{Indicadores de Qualidade das Escolas Municipais de Curitiba - IQEMC}

Este documento apresenta objetivos e critérios para avaliar escolas da rede municipal de Curitiba, no propósito de qualificar o trabalho escolar; que também contribui para apreender o que a secretaria de ensino espera de seus/suas profissionais.

O documento (CURITIBA, 2016a, p. 33) compreende a escola como um espaço formativo para docentes, demanda dos/as profissionais: a reflexão, a autonomia, a autoria de práticas e a contextualização da realidade que atua. Nesta perspectiva, requer dos/as profissionais a ação pela práxis, porque implica a relação de autonomia com a contextualização da realidade; ou seja: o sentido de autonomia é gerido coletivamente no e pelo contexto social.

Assim, o documento (CURITIBA, 2016a, p. 36) pontua o desenvolvimento profissional na perspectiva da práxis ao sugerir critérios que avaliam o trabalho por esta perspectiva formativa social e democrática.

\section{Projeto Político-Pedagógico da escola lócus da pesquisa - PPP}

O PPP é um documento que organiza as ações e concepções educacionais da escola. Esse documento da escola esteve desatualizado por alguns anos, foi atualizado em 2017.

O documento (CURITIBA, 2017, p. 15a) expõe características de um coletivo ativista, provocando a reflexão de uma formação mais ampla do que cognitiva, implicando a formação política envolta de criatividade. Nesse sentido, sugere a trans-formação docente à dimensão crítica que encontra no social os motivos de seu próprio trabalho. Esse é o contexto formativo da práxis contemplado no PPP da escola, que estando situada numa região de fragilidade social demanda muito mais dos/as profissionais esta criatividade política.

Percebemos alguma ênfase no enunciado (CURITIBA, 2017, p. 15b) “[...] que realmente possam propiciar ao estudante exemplos de práticas sociais transformadoras [...]". Entendemos a ênfase como uma demanda situada no próprio corpo docente, que registrado no PPP implica transformação de suas ações.

Em um aspecto geral, os documentos enunciam a formação pelo viés da práxis ao apontar o espaço formativo na escola e requerer a formação docente orientada pelas 
demandas sociais; por outro lado, o contrário está registrado, caso a interpretação dos assessoramentos pedagógicos penderem para a compreensão de controle da ação docente, como indicou Nóvoa (2009).

\section{O que relatam as professoresas de seus processos formativos docentes}

Buscamos, por meio das entrevistas, entender os seus processos de formação, como se tornaram professores/as, como o trabalho as "tans-formou", suas compreensões sobre a formação continuada, as possibilidades e os limites para tal. A interpretação dos sentidos não se esgota com as relações dialógicas por ser infinitas, contribui Bakhtin (1997), mas se procura aprofundar nos sentidos de cada enunciado. Com propósito de preservar o sigilo das professoras entrevistadas, utilizamos o código PEF (professora do ensino fundamental) seguido do seu número de identificação. Para além do cuidado com o sigilo, submetemos este artigo para a apreciação de ambas as professoras, com o intuito de obter seus consentimentos, de modo expresso, autorizando esta publicação. A formação em serviço é aquela que Freire (2001) chamou de permanente, pois para ele o/a professor/a não se forma em uma data marcada, ser professor/a é uma construção do trabalho cotidiano. Este paradigma está totalmente presente no discurso das professoras, ambas consideram a formação inicial (da academia) o fundamento de sua profissão, mas compreendem ser no trabalho que esse conhecimento se organiza para sustentar a sua profissão, que pode se observar no enunciado: "sem a formação eu não seria professora, a formação é essencial, só o dom, como assim, só o dom não tem como! Então eu retiraria isso de dom. É uma identificação".

O exercício da profissão vai lhes formando de forma distinta. A PEF1 tem como ponto de partida uma concepção mais idealizada, porém seu processo de formação permanente lhe permite refletir que: "o ser professora que eи queria ser mudou muito, a práxis faz a gente mudar, isso de escola para escola inclusive [...]”. Nesse sentido, a demanda social coloca o/a professor/a a refletir e modificar a sua postura e as suas ações. A objetivação do seu trabalho produz um fenômeno que é subjetivado, assim transforma o seu trabalho e a si mesmo/a, ao procurar atender a demanda qual está inserida.

A PEF2 destaca que seu ingresso na profissão docente advém de uma postura militante diante das questões sociais que viveu anteriores a formação docente. Revela essa condição quando explicita "eu tenho conhecimentos formais, saberes formais, mas eu 
tenho mais vivência, a minha história é mais longa; eu tenho um olhar mais crítico, eu acho que tenho um olhar mais crítico [...]". Considera que ser docente formada é apenas parte, pois tem uma história que precede e que se alonga a sua atuação profissional docente, portanto, compreende a sua formação como permanente e ainda contribui para um sentido existencial da sua própria formação, uma vez que sua existência precede a formação, a sua história de vida é mais longa, por isso a sua formação está escrita em sua história.

As professoras observam a práxis como relação teoria e prática. Afirmam que a prática se modifica a partir da demanda social e que a teoria deve ser questionada como se observa na afirmação de PEF1: "a teoria na prática não é exatamente igual, mas as que não são aplicáveis, o certo é considerar e discutir para dizer porque não são aplicáveis, eu tenho os porquês, pensei os porquês. A teoria está lá para ser questionada".

A reflexão teórica do próprio trabalho, destacada por PEF1 encontra eco em Cunha (1998), quando referencia a prática como o ponto de partida e de chegada ao processo de teorização, o que complementa Freire (1979) ao afirmar que a reflexão sobre a ação/trabalho é uma perspectiva da práxis em que o/a professor/a reflete a própria ação e isso modifica o seu modo de agir.

"Mostrar que outro mundo é possível, mostrar para este estudante que ele é capaz de romper com este sistema, que o coloca para a margem em que se encontra, e que pela educação pode ser transformado". Neste enunciado, PEF2 reposiciona a demanda social de transformação e rompimento com o sistema opressor, situando-o como uma demanda que a faz agir. A demanda social impulsiona a práxis, porque o/a professor/a reflete a sua ação para modificar a realidade, nesse sentido a ação docente é teleológica.

$\mathrm{Na}$ mesma direção, é possível perceber que PEF1 expressa o sentimento de importância, que qualifica o seu papel social numa relação com a sua própria existência, ao dizer que: "acho que na prática, a profissão de professor é importante, eu me sinto importante como professor/a, eu sinto que posso não fazer a diferença na vida de todos eles, mas que posso fazer diferença na sua formação como cidadãos". Percebe-se aí que a formação tem dimensão existencial, porque modifica o seu sentido racional através da subjetivação dos fenômenos de sua objetivação (trabalho) - Práxis.

Por outro lado, deve ser destacado o alerta que PEF2 traz quando reflete que, ao ser vivida a realidade concreta da escola e da comunidade no desempenho da docência, implica no enfrentamento dos reveses sociais da profissionalidade docente. Esse 
enfrentamento pode fazer com que os/as professores/as busquem na teoria a possibilidade de ampliar os seus recursos estratégicos. Por outro lado, alguns professores ativistas não encontram motivos para ampliar a sua prática, para eles basta a formação inicial. Ou ainda, podem agir por meio de um ativismo que, evidentemente, dispensa a teoria e reflexão, a prática passa ter fundamentação em si mesmo e por isso não há inovação e nem autonomia segundo Contreras (2012), há apenas a reprodução de ações.

Com essa reflexão, a professora PEF2, associa a teoria a toda sua a representação social e nesse sentido a recusa ao enfrentamento da realidade concreta de seus alunos/comunidade, não é teórica somente, senão é a contradição da produção cultural humana. No sentido da ênfase teórica, que a prática docente se distancia da demanda social para atender a ideologia, a epistemologia da prática docente se torna ingênua, ativista no sentido que apenas fazem sem conceber o que fazem, configurando uma prática antagônica da práxis.

O trabalho com sentido de transformação social é a práxis, esta que gera um fenômeno que se torna formativo ao ser subjetivado. Esta perspectiva formativa é a descrição particular que retroage ao coletivo, assim o modelo de formação pelo fenômeno da práxis retroage do/a professor/a individual ao corpo docente e vice-versa.

As entrevistas revelam ainda que compreendem que as trocas de experiências entre pares profissionais uma ação formativa, não apenas a troca de materiais senão, também, as trocas de sentidos, de angústias, que forma o coletivo. De outro modo negativo, ações 'do que não fazer' é citada como formativo, como contradição dialética crítica do intercâmbio no corpo docente.

Compreendemos com esses enunciados que a práxis atende uma demanda social de trans-formação. A proposição de trabalhar para atender a demanda social é uma forte característica da práxis que modifica o/a seu/sua agente, assim o/a professor/a objetiva o seu trabalho com intenções sociais e subjetiva os fenômenos do seu trabalho que o/a modifica como agente, a subjetivação dos efeitos (como fenômeno) do trabalho é transformador do/a professor/a. Contudo, a negativa desse processo também é possível, por meio na negação da demanda ou ingenuidade de sua própria prática docente. Se a formação pelo fenômeno da práxis é um processo existencial de objetivação e subjetivação do trabalho, a recursividade dessa formação é coletiva, logo a formação é do corpo docente, como se observa na troca entre pares profissionais. 


\section{O que observam os/as pedagogos/as sobre a formação continuada dos professores/as e sua relação com a práxis}

Com o propósito de ampliar a percepção sobre a formação continuada, buscamos nos discursos dos/as pedagogos/as as suas percepções acerca dos fenômenos formativos, que percebem no corpo docente. Nesta perspectiva, a entrevista é exotópica, pois falam de uma posição externa do fenômeno formativo do coletivo de professores/as.

Com propósitos de preservar o sigilo dos/as pedagogos/as que participaram da entrevista, daqui a diante serão utilizadas as siglas de PDG1 e PDG2, que significam pedagogo/a, seguido do número de identificação.

De modo amplo, os/as entrevistados/as afirmam que os/as professores/as chegam à escola necessitando desenvolver a sua prática, embora formados/as pela academia, precisam relacionar a teoria com a sua prática numa perspectiva formativa, para além de uma concepção idealizada.

A relação entre a existência e a profissão é compreendida por PDG2 como trajetória de vida, onde a "vida da pessoa não está separada da trajetória da vida da universidade [...] não existe vida particular, não existe. Para mim é tudo uma coisa só [...] como eu chego ali e bato ponto e sou outra pessoa e na rua outra?" A afirmação de que não há distinção entre 'vida pessoal' e 'vida profissional' está apoiada por Nóvoa (2009). Desse modo, a formação docente tem esta dimensão existencial reafirmada pelos enunciados e autores, que destoa da posição pragmatista que tenta separar estas posições numa esfera abstrata. Assim:

não há prática que, como no pragmatismo, tem como critério de verdade o êxito, a eficácia da prática individual. Aqui o prático é reduzido ao utilitário, ou seja, à correspondência de um pensamento com meus interesses. Para o marxismo é a prática social que revela a verdade ou falsidade, isto é, a correspondência ou não de um pensamento com a realidade (PIMENTA, 2010, p. 92).

Nessa perspectiva pragmatista, há professores/as muito bons, referenciados por sua especialização do conteúdo, mas como afirma PDG1 não enfrentam ou tem dificuldades com situações conflitantes do cotidiano escolar: "elas são excelentes (em domínio de conteúdo) e querem alunos excelentes [...] esse aluno é o negativo do trabalho dela, mas ser professor é isso, é buscar atender todos eles". Desse modo, apesar de especializado/a o/a professor/a não atende à demanda, porque a sua especialização o/a coloca em outro patamar que não implica em resolver conflitos, porque a sua 
especialização deve garantir um trabalho "com quem esteja à altura", ou seja, o/a estudante "ideal".

A recusa à demanda social revela uma postura individualista em que, na fragmentação do trabalho em relação a existência, o sujeito não se compreende na mesma esfera social e/ou não faz o exercício de alteridade, assim, não compreende a demanda social como sua responsabilidade.

O PDG1 exprime a dimensão da práxis que a escola está envolta e, também, a resistência docente em enfrentar a demanda social com o seu trabalho, quando destaca que ao trabalhar em uma escola de periferia com baixo poder econômico e sérios problemas sociais, não tem como "ser resistente a crítica da sociedade, tem que se aproximar da sociedade para poder entender e poder trabalhar. Esta práxis em relação a aprendizagem tem que ser, também, em relação a sociedade - sem isso não tem como ser preparado". Na compreensão de PDG1 o empenho social deve ter tanta força quando o empenho didático, imbricado de proposições sociais - configura uma compreensão de práxis que o corpo docente recusa.

Assim como os/as professores/as entrevistados, o PDG2 destaca que outra tendência formativa é o ativismo ingênuo, que o/a professor/a não concebe a sua própria prática e, ainda, recusa a dimensão teórica da sua formação, e ao não refletirem sobre sua prática acabam buscando uma formação como "um livro de receitas", que as utiliza sem concepção da própria prática. Esta característica docente está muito aquém da perspectiva da práxis, pois o/a profissional ignora a demanda social e, também, o significado do próprio trabalho.

Por outro lado, PDG1 explica como o/a professor/a deve estar atento/a ao seu contexto, pois o ambiente deve modificar a prática docente para o enfrentamento de sua demanda. A demanda social impulsiona o/a professor/a a buscar novos conhecimentos e assim o/a professor/a se trans-forma - a orientação da formação pela práxis é a realidade social.

O PDG2 oferece algum rigor ao afirmar que a prática educacional não modifica o/a professor/a, mas é a relação entre a prática (objetivação) com a teoria (subjetivação) que modifica o/a professor/a. Quem faz isso é a pessoa, em seu contexto existencial que é demandante. Nessa direção, PDG2 afirma: “mudam quando não tem outra saída, estão numa encruzilhada. [...] A prática delas (professoras) muda quando fazem a ligação com a teoria que aprenderam na academia ou aprenderam fora dela". 
Contudo, numa perspectiva coletiva as mudanças geralmente não ocorrem porque obedecem unicamente a uma decisão estatística, não ocorre mudança de pensamento, afirmou PDG2. Continua, "o convencimento é a troca de experiência e a transformação do grupo, daí é práxis". Nessa toada, buscamos o olhar de Freire:

[...] uma das coisas gostosas no jogo democrático é que não basta você estar convencido do acerto de suas ideias e do acerto de sua prática. Você precisa demonstrá-la e convencer os demais. Diria até que, em muitos casos, você precisa converter (FREIRE, 2001, p. 74).

O caso dessa escola apresentou professoras que concebem e trabalham pela perspectiva da práxis, mas por outro lado, os/as pedagogos/as revelam que o corpo docente não apresenta esta característica, havendo tendências pragmatistas de ações individualistas e tendências ativistas em que o/a professor/a não concebe a própria prática.

Os enunciados dessa seção oferecem rigor a compreensão da formação docente pelo fenômeno da práxis, como: a reafirmação da existência nesta perspectiva formativa, a demanda social como impulsionador da práxis, a relação objetivação e subjetivação como caráter formativo e a compreensão do convencimento como ação democrática de transformação do corpo docente.

\section{Considerações provisórias}

Ao problematizar a formação, consideramos como ela é definida pelas políticas e documentos, bem como o modo como se efetiva no cotidiano da escola, com o objetivo de entender suas possibilidades e limites de se viabilizar por meio da práxis docente.

Em um exercício de análise dialética acerca do entendimento da possibilidade recursiva da práxis na formação docente, podemos perceber que apesar dos documentos citados neste artigo, sugerirem o trabalho coletivo e democrático, as condições materiais de exercício da docência e da formação inicial, remetem para um exercício individual e descolado de decisões coletivas, quando existentes, contrariando alguns postulados básicos como defende Nóvoa (2009) em que o trabalho coletivo é formativo, pois é no diálogo que se inova as práticas docentes.

Constatamos por meio das entrevistas e das observações, que o caso da escola pesquisada, apresenta um corpo docente integrado por muitos/as professor/as, que trabalham, de forma geral, com orientação pragmatista em uma comunidade que demanda 
revolução. Poucos/as professores/as se preocupam com a práxis do trabalho (no sentido deste texto) e outros/as articulam o seu trabalho como ativismo e, não poucos, trabalham com ingenuidade.

Os/as professores/as entrevistadas, que apontaram o ativismo como tendência formativa, a localizam como uma formação de início de carreira, relacionada à preocupação de atender a demanda educacional com a efetivação de muitos afazeres. A prática docente ativista é um limitante ou obstáculo para a formação por meio da práxis, porque, apesar de relacionar a existência com a objetivação, são docentes que muito fazem e aplicam muito do seu tempo existencial para produzir, porém não realizam a subjetivação de seu trabalho docente.

Outro limite ou obstáculo para a formação por meio da práxis é apontada pelos/as pedagogos/as entrevistadas, como sendo a tendência formativa pragmática. Enunciam esta tendência como predominante na escola, relatam que sendo bons professores (tecnicamente) articulam a teoria com a prática, porém não se flexibilizam e não modificam a sua prática para dialogar com a demanda social suas e de seus estudantes. Assumindo essa posição, estes/as profissionais se posicionam existencialmente afastados/as da dimensão social da escola e exercitam a ideia de separar vida/processo histórico pessoal da profissional.

Apesar da ocorrência das tendências pragmáticas, ativistas e ingênuas, a práxis, como possibilidade de formação docente, se apresenta entre os/as professores/as quando refletidas em seus discursos e exemplos de suas práticas. Como podemos perceber, são processos formativos constituídos no decorrer de suas carreiras.

As professoras entrevistadas relatam a sua história de como passaram de uma tendência formativa pragmatista para a tendência formativa da práxis; elas encontraram na demanda social, presente na escola, a correlação com a sua própria existência de dimensão social. Assim, relatam que subjetivando esta demanda social, pela empatia existencial, modificaram as suas práticas e perspectivas de ensino, construindo uma concepção educacional que ultrapassa a demanda técnica e cognitiva e passa a se orientar pela demanda social como elemento de diálogo entre a vida e o conhecimento sistematizado.

Por fim, podemos responder nossa pergunta inicial, a qual intitula este artigo: a práxis como fenômeno formador do/a docente: um caminho possível? Sim! Porém, com a clareza que este processo de formação, por meio da práxis, se dá e dará no tensionamento 
com as demais tendências formativas hegemônicas, pois representam posições políticas, decorrentes de disputas de projetos de sujeitos e de sociedade.

Portanto, muito mais do que uma simples opção formativa, a concepção da práxis, enquanto fenômeno formativo, é política, pois é na compreensão da demanda social, na intencionalidade de transformação a fim de humanização que esta tendência se torna possível enquanto opção de trans-formação do/da docente e da educação.

\section{REFERÊNCIAS}

BAKHTIN, Mikhail. Estética da criação verbal. Tradução de Maria Emantina Galvão G.Pereira. 2 ed. São Paulo: Martins Fontes, 1997.

BRASIL. Diretrizes Curriculares Nacionais da Educação Básica. Brasília: MEC, 2013. CONTRERAS, José. A autonomia de professores. Tradução de Sandra Trabucco Valenzuela. 2 ed. São Paulo: Cortez, 2012.

CUNHA, Maria Isabel. O professor universitário na transição de paradigmas. São Paulo: JM Editora, 1998.

CURITIBA. Projeto Político-Pedagógico. Curitiba: SME, 2017.

CURITIBA. Currículo do Ensino Fundamental $1^{\circ}$ ao $9^{\circ}$ ano. Curitiba, SME, 2016.

CURITIBA. Indicadores de Qualidade das Escolas Municipais de Curitiba. Curitiba: SME, 2016a.

CURITIBA. Diretrizes Curriculares para a Educação Municipal de Curitiba. Curitiba: SME, 2006

FREIRE, Paulo. Conscientização: teoria e prática da libertação: uma introdução ao pensamento de Paulo Freire. São Paulo: Cortez \& Moraes, 1979.

FREIRE, Paulo. Pedagogia da Autonomia. 25 ed. Rio de Janeiro: Paz e Terra, 1996.

FREIRE, Paulo. A Educação na Cidade. 5 ed. São Paulo: Cortez Editora, 2001.

MARX, Karl.; ENGELS, Friedrich. A ideologia alemã. 2 ed. São Paulo: Martins Fontes, 2001.

NÓVOA, Antônio. Professores imagens do futuro presente. Educa: Lisboa, 2009.

TRIVIÑOS, Augusto Nibaldo Silva. Introdução à pesquisa em ciências Sociais: a pesquisa qualitativa em educação. São Paulo: Atlas, 1987. 
VÁZQUEZ, Adolfo Sánchez. Filosofia da práxis. Tradução de Luiz Fernando Cardoso. 3. ed. Rio de Janeiro: Paz e Terra, 1977.

VIEIRA PINTO, Álvaro. Sete lições sobre a educação de adultos. São Paulo: Cortez, 1982.

VIEIRA PINTO, Álvaro. Ciência e existência: problemas filosóficos da pesquisa científica. 3 ed. São Paulo: Paz e Terra, 1985.

\section{Como referenciar este artigo}

RAIMUNDO, Jerry Adriano; FAGUNDES, Maurício. A práxis como fenômeno formador do/a docente: um caminho possível?. Revista Ibero-Americana de Estudos em Educação, Araraquara, v. esp, n. 3, p. 1935-1951, dez., 2018. E-ISSN: 1982-5587. DOI: 10.21723/riaee.unesp.v13.iesp3.dez.2018.10891

Submetido em: 15/01/2018

Revisões requeridas: 10/05/2018

Aprovado em: 16/08/2018 